\title{
Clinical profile and outcome of the patients admitted in PICU in tertiary hospital.
}

1. MBBS, FCPS (Pediatric Medicine)
Assistant Professor Paediatric
Medicine
Nishtar Medical University, Multan.
2. MBBS, FCPS (Paediatric Medicine)
Associate Professor Paediatric
Medicine
The Children's Hospital \& ICH,
Multan.
3. MBBS, FCPS (Pediatric Medicine)
Assistant Professor Pediatric
Medicine
Nishtar Medical University, Multan.
4. MBSS
Post Graduate Resident Pediatric
Medicine
Nishtar University Hospital, Multan.

Correspondence Address:

Dr. Asim Khurshid

Department of Pediatric Medicine

The Children's Hospital \& ICH, Multan.

Article received on:

02/09/2020

Accepted for publication:

$19 / 11 / 2020$

\section{Maria Saleem 1 , Asim Khurshid², Amna Wajdan ${ }^{3}$, Muhammad Salman Zafar ${ }^{4}$}

ABSTRACT... Objectives: To analyze the clinical profile, etiologies and outcome of seriously ill patients admitted in Pediatric Intensive Care Unit (PICU). Study Design: Cross Sectional study. Setting: PICU of Nishtar Medical Hospital, Multan, Pakistan. Period: January 2018 to December 2018. Material \& Methods: During the study period, a total of 150 children, aged 1 to 12 years, with better prognosis and post-surgical cases requiring intensive care were registered. Age, gender, cause for hospitalization (clinical, surgical or emergency), length of PICU stay, diagnosis and outcome were recorded for all patients. Results: During the year of the study, $83(55.3 \%)$ children were noted to be male. The mean age was $56.9+12.5$ months. Mechanical ventilation was done in $62(41.3 \%)$ patients. Major indications for admission to the PICU were respiratory disorders $(21.5 \%)$, followed by sepsis $(11.4 \%)$ and meningitis $(8.1 \%)$. Majority, 80 (53.3\%) patients improved and were shifted to ward and later discharged while 27 (18.0\%) expired. Conclusion: Most of the children admitted in the PICU were male, aged below 5 years. Most common indication for admission in the PICU were respiratory disorders followed by sepsis and meningitis.

Key words: $\quad$ Critical Care, Diagnosis, Expired, Pediatric Intensive Care.

Article Citation: Saleem M, Khurshid A, Wajdan A, Zafar MS. Clinical profile and outcome of the patients admitted in PICU in tertiary hospital. Professional Med J 2021; 28(4):548-551. https://doi.org/10.29309/TPMJ/2021.28.04.6052

\section{INTRODUCTION}

Optimum care in the pediatric intensive care unit depends on the expertise of the health-care professionals, the availability of the resources, and evidence based treatment guidelines. ${ }^{1}$ Pediatric Intensive Care Unit (PICU) role is vital in the care of seriously ill children. PICU primarily functions for the maintenance of the vital organ function in seriously-ill children. ${ }^{2}$

The pediatric critical care not only decreases the mortality as well as morbidity. It should also provide comfort and support to the child's family. ${ }^{1}$ The under-five mortality situation is still alarming despite of improved health facilities. According to $\mathrm{WHO}$ about 5.9 million children under age five died in 2015, i.e., 16,000 every day, and the major causes of death in under-five-year-old children in developing countries are preventable and treatable. ${ }^{3}$ By improving the intensive care services mortality rates can be reduced by $15 \%$ to $60 \%$, and its role is unquestionable. ${ }^{4,5}$
In the last two decades, the ICUs are increasing in number due to improvements in life-saving technologies. Approximately $15-20 \%$ of hospital budgets are now spent in care of seriously ill children by the ICUs so it is important to improve the safety of medical care due to this high cost. ${ }^{6}$ There are many indicators of mortality and frequency of complications, like nosocomial infections in ICUs, with much emphasis on quality improvement measures and outcome.

The aim of this study was to establish a profile for patients admitted to PICU of a universitybased tertiary pediatric hospital, describing the demographics of patients, diagnosis, and outcome. This would allow identifying the magnitude of each illness that needed intensive care and redistribution of resources.

\section{MATERIAL \& METHODS}

It was a cross sectional study conducted over one year from January 2018 to December 2018 
including all patients admitted to pediatric intensive care unit (PICU) of "Nishtar Medical University, Multan". Approval from "institutional ethical committee" was taken. Written consent was sought from parents/guardians of all study participants.

During the study period, a total of 150 children, aged 1 to 12 years, with better prognosis and post-surgical cases requiring intensive care were registered. Children who died within $1^{\text {st }} 24$ hours, or those with congenital malformations like congenital heart disease (labeled on clinical examination and appropriate investigations), who were discharged from the unit within 24 hours of admission or those with malignancies were excluded (on clinical examination and appropriate investigations).

Information about admissions in PICU, transfers out, discharges, and deaths were analyzed. The following variables were included for analysis: Age, gender, cause for hospitalization (clinical, surgical or emergency), length of PICU stay, diagnosis and outcome. Outcome was classified as shifting back to the main pediatric wards, discharges, left against medical advice, and expiry. Data were extracted from the patient's files filled by resident. Extracted data included demographic characteristics: age and sex, clinical characteristics like provisional diagnosis and outcome along with outcomes including length of stay (LOS), referral to general ward, or death were also noted. SPSS version 26.0 was used for data analysis. Data were tabulated and analyzed using frequency and percentage. Nominal data were compared using the $\chi^{2}$ tests. $P$ values less than 0.05 were considered significant.

\section{RESULTS}

During the year of the study, the total number of patients admitted to this PICU was 150 out of which $83(55.3 \%)$ were male. The mean age was $56.9+12.5$ months. Mechanical ventilation was done in $62(41.3 \%)$ patients (Table-I).

Major indications for admission to the PICU were respiratory disorders $(21.5 \%)$, followed by sepsis $(11.4 \%)$, meningitis $(8.1 \%)$ and diabetes ketoacidosis (8.1\%) and others in the order given in Table-II.

Sixty two patients (41.3\%) required ventilatory support during the course of their PICU stay out of which 21 (33.9\%) patients expired. Majority, 80 (53.3\%) patients improved and were shifted to ward and later discharged. Twenty three patients (15.3\%) discharged directly from PICU. Twenty (13.3\%) left treatment in between due to personal reasons (Table-III).

\begin{tabular}{|c|c|c|}
\hline \multicolumn{2}{|c|}{ Variables } & Number (\%) \\
\hline \multirow{2}{*}{ Gender } & Male & 83 (55.3\%) \\
\hline & Female & 67 (44.7\%) \\
\hline \multirow{2}{*}{ Age Groups (years) } & $<5$ & 96 (64.4\%) \\
\hline & $>5$ & $53(35.6 \%)$ \\
\hline \multirow{2}{*}{ Ventilation Done } & Yes & $62(41.3 \%)$ \\
\hline & No & 88 (58.7\%) \\
\hline \multirow{2}{*}{ Expired } & Yes & 27 (18.0\%) \\
\hline & No & $123(82.0 \%)$ \\
\hline \multicolumn{3}{|c|}{ Table-I. Patients characteristics } \\
\hline Indications & $\begin{array}{l}\text { No. of Patients } \\
(\%), n=150\end{array}$ & $\begin{array}{c}\text { Expired (\%), } \\
n=27\end{array}$ \\
\hline Pneumonia & $37(24.7 \%)$ & $6(22.2 \%)$ \\
\hline Meningoencephalitis & $18(12.0 \%)$ & $4(14.8 \%)$ \\
\hline Sepsis & $17(11.3 \%)$ & $5(18.5 \%)$ \\
\hline DKA & $12(8.0 \%)$ & $1(3.7 \%)$ \\
\hline Poisoning & $9(6.0 \%)$ & $2(7.4 \%)$ \\
\hline AFP / GBS & $10(6.7 \%)$ & $2(7.4 \%)$ \\
\hline Cardiac failure & $7(4.7 \%)$ & 0 \\
\hline Renal & $10(6.7 \%)$ & $1(3.7 \%)$ \\
\hline F.B & $9(6.0 \%)$ & 0 \\
\hline Trauma & $6(4.0 \%)$ & $1(3.7 \%)$ \\
\hline Asthma & $3(2.0 \%)$ & $1(3.7 \%)$ \\
\hline Hepatic failure & $2(1.3 \%)$ & $1(3.7 \%)$ \\
\hline Post op & $5(3.3 \%)$ & $2(7.4 \%)$ \\
\hline Others & $5(3.3 \%)$ & $1(3.7 \%)$ \\
\hline
\end{tabular}

Table-II. Indications for Admission to the PICU and their relationship with outcome

\begin{tabular}{|l|c|c|}
\hline \multicolumn{1}{|c|}{ Outcome } & Frequency & Percent \\
\hline Shifted & 80 & 53.3 \\
\hline Lama & 20 & 13.3 \\
\hline Expired & 27 & 18.0 \\
\hline Discharge & 23 & 15.3 \\
\hline
\end{tabular}

Table-III. Outcome among patients admitted to PICU $(n=150)$

\section{DISCUSSION}


The results of study regarding indication of admission are comparable to a study from Canada which described the frequency, characteristics and outcomes of children who required admission to PICU and this study showed majority of admissions being infants and respiratory issues being the major indication for PICU admission as our study also showed that $24.7 \%$ admissions were due to respiratory cause. ${ }^{7}$ Another study done in India by Dr. Gaurav Mukhija showed major indication for admission to the PICU was respiratory (46.2\%), followed by cardiovascular $(41.2 \%)$, central nervous system $(10.8 \%)$. The major (40.06\%) single primary diagnosis was sepsis. ${ }^{8}$

In this study, $55.3 \%$ patients were male and $64.4 \%$ were under 60 months of age which correlates with a study published in journal of college of physicians and surgeons Pakistan by Haque A et al where most children, $62.5 \%$ were under 5 years of age. This study revealed the male to female sex ratio to be 2.03:1.2 Another study done in the PICU of Kurnool Medical college and hospital in 2016 found that $83 \%$ cases were under 5 years of age which correlates with our study. ${ }^{9}$ This is comparable to a study published by El Halal MG et al, from Brazil where it was reported that majority of the patients, $78.3 \%$ were under 5 years of age. ${ }^{10} \mathrm{~A}$ study conducted by Abhulimhen-lyoha $\mathrm{Bl}$ et $\mathrm{al}^{5}$, revealed that $72.4 \%$ patients were aged less than 5 years comparable to our study. ${ }^{11}$

In our study out of 149 patients the mortality was $18.1 \%$. In a study from Pakistan by Haque A et al, mortality rate was found to be $11.9 \%$ in their PICU. ${ }^{12}$ Shah GS et al, found that in their centre the mortality was $12.6 \% .{ }^{13}$ Some other studies have also shown mortality comparable to our study. Another study from Pakistan by Haque A et al and Bano S et al, reported a mortality of $35 \%$ in their institute. ${ }^{2}$

In terms of limitations of this study, we were unable to have a proper assessment of the severity scoring using tools like "Pediatric Risk of Mortality (PRISM)" and "Pediatric Index of Mortality (PIM)" among study cases. Being a single center study meant that the results of this study cannot be generalized.

\section{CONCLUSION}

Most of the children admitted in the PICU were male, aged below 5 years. Most common indication for admission in the PICU were respiratory disorders followed by sepsis and meningitis.

Copyright@ 19 Nov, 2020.

\section{REFERENCES}

1. Earan SK, Dhandapani L, Arunagirinathan A, Kantamneni S. Clinical spectrum and epidemiological profile of patients admitted to pediatric intensive care unit at a tertiary care centre in South India. Int J Sci Stud. 2016; 4(3):187-191.

2. Anwarul $H$, Surraiya B. Clinical profile and outcome in a paediatric intensive care unit in Pakistan. Journal of the College of Physicians and Surgeons Pakistan. 2009; 19(8):534-535.

3. The epidemiological profile of pediatric patients admitted to the general intensive care unit in an Ethiopian university hospital. Int J Gen Med. 2015; 8:3-6.

4. Butt W, Shann F, Tibballs J, Jacqueline W, Lucy C, Louise $B$, et al. Long-term outcome of children after intensive care. Crit Care Med. 1990; 18(9):961-965.

5. Gemke R,Bonsel GJ,Van Vught A. Longterm survival and state of health after pediatric intensive care. Arch Dis Child. 1995; 73(3):196-201.

6. Rady HI. Profile of patients admitted to pediatric intensive care unit, Cairo University Hospital: 1-year study. Ain-Shams J Anaesthesiol 2014; 7:500-503.

7. Krmpotic K, Lobos AT. Clinical profile of children requiring early unplanned admission to the PICU. Hosp Pediatr. 2013; 3(3):212-218.

8. Mukhija G, Chandra S, Prasad PL. Clinical profile of patients admitted to the PICU of a tertiary care teaching hospital. nt J Pediatr Res. 2017; 4(2):125-127.

9. Aruna JK, Korisipati A. A study on clinical profile and outcome of patients in PICU (paediatric intensive care unit) at tertiary care unit. Int $\mathrm{J}$ Contemporary Pediatr. 2019; 6(2):757-760.

10. El Halal MG, Barbieri E, Mombelli Filho R, de Andrade Trotta E, Carvalho PR. Admission source and mortality in a pediatric intensive care unit. Indian $\mathrm{J}$ Critical Care Med. 2012:16(2); 81-6. 
11. Abhulimhen-lyoha BI, Pooboni SK, Vuppali NK. Morbidity pattern and outcome of patients admitted into a pediatric intensive care unit in India. Indian J Clinical Med. 2014; 5:S13902.

12. Haque A, Siddiqui NR, Jafri SK, Hoda M, Bano S, Asad Mian. Clinical profiles and outcomes of children admitted to the paediatric intensive care unit from the emergency department. J Col Phys Surg Pak. 2015:25(4); 301-3.
13. Shah GS, Shah BK, Thapa A, Shah L, Mishra OP. Admission patterns and outcome in a pediatrics intensive care unit in Nepal. British $\mathrm{J}$ Med Med Res2014; 4(30):4939-4945.

\section{AUTHORSHIP AND CONTRIBUTION DECLARATION}

\begin{tabular}{|c|l|l|l|}
\hline Sr. \# & \multicolumn{1}{|c|}{ Author(s) Full Name } & \multicolumn{1}{|c|}{ Contribution to the paper } & Author(s) Signature \\
\hline 1 & Maria Saleem & $\begin{array}{l}\text { Data interpretaion, Literature } \\
\text { review. } \\
\text { Study concept, Drafting, } \\
\text { Supervision, Proof reading. } \\
\text { Methodology, Literature } \\
\text { review, Discussion }\end{array}$ \\
\hline 4 & Asim Khurshid & Amna Wajdan & $\begin{array}{l}\text { Muhammad Salman Zafar } \\
\text { Data collection, Data analysis }\end{array}$ \\
\hline
\end{tabular}

